\title{
$N$-Acetylcysteine and Endothelial Cell Injury by Sulfur Mustard
}

Kevin B. Atkins, ${ }^{1}$ Irfan J. Lodhi, ${ }^{2}$ Lauren L. Hurley ${ }^{2}$ and Daniel B. Hinshaw ${ }^{1,2, *}$

${ }^{1}$ University of Michigan Medical School, Ann Arbor, MI 48105, USA

${ }^{2}$ VA Medical Center, Ann Arbor, MI, USA

Key words: $N$-acetylcysteine; endothelial cell injury; glutathione; GSH; NFкB.

Understanding the underlying mechanisms of cell injury and death induced by the chemical warfare vesicant sulfur mustard (HD) will be extremely helpful in the development of effective countermeasures to this weapon of terror. We have found recently that HD induces both apoptosis and necrosis in endothelial cells (Toxicol. Appl. Pharmacol. 1996; 141: 568-583). Pretreatment of the endothelial cells for $20 \mathrm{~h}$ with the redox-active agent $N$-acetyl-L-cysteine (NAC) selectively prevented apoptotic death induced by HD. In this study, we tested the hypotheses that pretreatment with NAC acts through two different pathways to minimize endothelial injury by HD: NAC pretreatment acts via a glutathione (GSH)-dependent pathway; and NAC pretreatment acts to suppress HD-induced activation of the nuclear transcription factor NFкB. We used a fluorescence microscopic assay of apoptotic nuclear features to assess viability and electrophoretic mobility shift assays (EMSAs) to assess the activity of NF $\mathrm{B}$ following exposure to HD. The cells were treated with 0-10 mM GSH for $1 \mathrm{~h}$ prior to and during exposure to 0 or $500 \mu \mathrm{M}$ HD for 5-6 h. Cells were also treated with $50 \mathrm{mM}$ NAC or $200 \mu \mathrm{M}$ buthionine sulfoximine (BSO), an inhibitor of GSH synthesis, alone or in combination overnight prior to exposure to 0 or $500 \mu M$ HD for 5-6 h. Externally applied GSH up to a concentration of $5 \mathrm{mM}$ had no toxic effect on the cells. Mild toxicity was associated with $10 \mathrm{mM}$ GSH alone. There was a dose-related enhancement of viability when 2.5 and $5 \mathrm{mM}$ GSH were present during the HD exposure. Pretreatment with BSO alone had no discernible toxicity. However, pretreatment with this inhibitor of GSH synthesis potentiated the toxicity of HD. Pretreatment with $50 \mathrm{mM}$ NAC, as previously reported, provided substantial protection. Combining pretreatment with both BSO and NAC eliminated the protective effect of NAC pretreatment alone on HD injury. These observations are highly suggestive that NAC enhances endothelial survival via GSH-dependent effects and confirms and extends the work of others with different models that externally supplied GSH alone may be a fairly effective countermeasure against HD injury of endothelium. We next examined the hypothesis that HD may activate the nuclear transcription factor NFкB by performing EMSAs with nuclear extracts of endothelial cells following exposure to 0,250 or $500 \mu \mathrm{M}$ HD. This demonstrated an up to 2.5 -fold increase (scanning densitometry) in activation of NFKB binding to its consensus sequence induced by $500 \mu \mathrm{M}$ HD after 5 h of HD exposure. Paradoxically, treatment of the endothelial cells alone with $50 \mathrm{mM}$ NAC activated NFKB, although HD-induced activation of NFкB was partially suppressed by NAC at $5 \mathrm{~h}$. Factor NFкB is an important transcription factor for a number of cytokine genes (e.g. tumor necrosis factor, TNF), which can be activated following stress in endothelial cells. Taken together, these observations suggest that the protective effects of NAC may be mediated by enhanced GSH synthesis. The increased GSH may act to scavenge HD and also prevent oxidative activation of NFKB. Under some conditions, NAC may act as an oxidizing agent and thus increase NFKB activity. The NFKB-dependent gene expression may be important in inducing endothelial cell death as well as in generating a local inflammatory reaction associated with the release of endothelial-derived cytokines. Copyright (c) 2000 John Wiley \& Sons, Ltd.

\section{INTRODUCTION}

In recent years there has been a growing concern about the proliferation of chemical weapons and an increasing interest in the ability to combat them. One such agent, sulfur mustard (HD), is used as a vesicant. Sulfur mustard is both mutagenic and carcinogenic, most likely as a result of DNA damage due to alkylation. ${ }^{1}$ * Correspondence to: D. B. Hinshaw, University of Michigan Medical
School, Ann Arbor, MI 48105, USA.
Exposure to HD causes irritation, edema, vesication, ulceration and ultimately necrosis. These effects are dependent upon the dose and location of HD exposure.

Endothelial cells are one target of HD-mediated injury. Increased capillary leakage has been observed during HD injury. ${ }^{2}$ We have also found that cultured vascular endothelial cell monolayers demonstrate increased permeability in response to $\mathrm{HD}^{3}$ This increased permeability may be the result of altered endothelial morphology. Vascular endothelial cells exposed to HD undergo microtubule depolymerization, disruption of long actin filament stress fibers, loss of 
adherence and ultimately apoptosis or necrosis. ${ }^{4} \mathrm{~N}$ Acetylcysteine (NAC) induces reorganization of endothelial stress fiber networks and prevents HD-induced cellular rounding, loss of adherence and apoptosis. ${ }^{4}$

$\mathrm{N}$-Acetylcysteine is an antioxidant and redox-active agent reported to prevent apoptosis in lymphocytes, neurons and vascular endothelial cells. ${ }^{5}$ In addition, this thiol-containing compound is a precursor for glutathione synthesis. Glutathione, a cysteine-containing tripeptide, plays an important role in the detoxification of xenobiotics and in the scavenging of reactive oxygen species and free radicals. It has been demonstrated that some of the major metabolic products of HD are glutathione conjugates ${ }^{6}$ and that HD is excreted as a glutathione metabolite. ${ }^{7}$ In rat lung tissue slices exposed to HD there was a depletion of intracellular glutathione. ${ }^{8}$ Glutathione levels are reduced in neuroblastoma-glioma hybrids and human peripheral lymphocytes exposed to HD..$^{9,10}$

Sulfur mustard exposure of the human keratinocyte cell line SVK-14 is accompanied by decreased viability. ${ }^{11}$ Pretreatment with glutathione increased the survivability of SVK-14 cells exposed to HD. Pretreatment of cultured rat lung slices with cysteine esters, which raise cellular cysteine levels available for glutathione synthesis, is reported to be protective in HD injury. ${ }^{12}$ Reciprocally, reduction of cellular glutathione prior to HD exposure sensitized cells to the cytotoxic effects of HD. ${ }^{10}$ In these same experiments, pretreatment with NAC, which raised intracellular glutathione, was protective against HD-induced cytotoxicity. Therefore, it was of interest to determine in our model whether there is any relationship between the protective effects of NAC and glutathione levels. Furthermore, depletion of glutathione is associated with potentiation of tumor-necrosis-factor-mediated activation of the transcription factor NFKB in L6 myoblasts. ${ }^{13}$ Because NAC has been demonstrated to inhibit the activation of $\mathrm{NF \kappa B}$, we investigated whether this transcription factor might be activated in response to HD injury.

\section{METHODS AND MATERIALS}

\section{Cell culture}

Bovine pulmonary artery endothelial cells (National Institute of Aging, Aging Cell Culture Repository, Camden, NJ) were grown in F12 (Ham) nutrient mixture supplemented with $10 \%$ fetal bovine serum and antibiotics (Gibco, Grand Island, NY) and maintained at $37^{\circ} \mathrm{C}$ under a $5 \% \mathrm{CO}_{2}$-humidified atmosphere. Cells were passaged using $0.05 \%$ trypsin and $0.02 \%$ EDTA (Gibco) and were at confluence for all experiments reported herein.

\section{Cell viability}

Confluent endothelial cells pretreated or not with glutathione-modifying agents were subsequently treated with or without $500 \mu \mathrm{M}$ HD for $6 \mathrm{~h}$. The medium was then removed and saved and the cells were harvested using trypsin/EDTA. The harvested cells and media were centrifuged and the resulting pellet resuspended. An aliquot was stained with a dye mixture $(10 \mu \mathrm{M}$ acridine orange and $10 \mu \mathrm{M}$ ethidium bromide) and examined by fluorescence microscopy according to the criteria described previously. ${ }^{4}$

\section{Glutathione assay}

Endothelial cells treated with or without $500 \mu \mathrm{M}$ HD in the presence or absence of pretreatment were harvested as described above. The cell pellet $(0.25-0.5 \times$ $10^{6}$ cells) was resuspended in $50 \mu \mathrm{l}$ of $0.2 \%$ TritonX100 containing $2.5 \%$ sulfosalicylic acid. The cells were vortexed and then centrifuged at $12000 \mathrm{rpm}$ for $5 \mathrm{~min}$. Then $25 \mu \mathrm{l}$ of supernatant was transferred to a tube. Total cellular glutathione (GSH) was subsequently measured as described. ${ }^{14}$

\section{Electrophoretic mobility shift assay}

Confluent endothelial cells were treated with or without $50 \mathrm{mM}$ NAC for at least $16 \mathrm{~h}$. Cells were then treated with or without $250 \mu \mathrm{M}$ HD or $500 \mu \mathrm{M}$ HD for 2 or $5 \mathrm{~h}$. Cells were harvested by scraping and the cells and media were pelleted. The pellet was processed for nuclear protein as described. ${ }^{15}$ The nuclear extracts were normalized for protein content (Bio-Rad, Hercules, CA) and analyzed for binding to a radiolabeled consensus nuclear factor sequence (NFkB; 5'GGGGACTTTCCGCTGGGGACTTTCCAGGGGGACTTTCC $\left.3^{\prime}\right)$ as described. ${ }^{16}$ Specific binding was determined utilizing a 100-fold excess unlabeled NFкB sequence.

\section{Statistics}

Data were analyzed by a two-tailed Student's $t$-test.

\section{RESULTS}

\section{Effects of glutathione-altering conditions on endothelial cell viability following Sulfur mustard exposure}

The agents buthionine sulfoximine (BSO) and NAC were used to alter the synthesis of GSH in endothelial cells prior to HD exposure. Pretreatment of the endothelial cells with $0.2 \mathrm{mM}$ BSO (a specific inhibitor of $\gamma$-glutamyl cysteine synthetase) did not alter the viability of uninjured control endothelial cells (Table 1). However, GSH depletion with BSO pretreatment did potentiate the toxic effect of $500 \mu \mathrm{M} H D$ on endothelial viability, which was largely demonstrated as an increase in the number of necrotic cells detected $6 \mathrm{~h}$ after HD exposure (Table 1). The increased viability of endothelial cells exposed to $500 \mu \mathrm{M}$ HD that had been pretreated with $50 \mathrm{mM}$ NAC was abrogated by concurrent pretreatment with BSO (Table 1).

When exogenous GSH $(0-10 \mathrm{mM})$ was present during HD exposure, there was a dose-dependent increase in survival of endothelial cells exposed to $500 \mu \mathrm{M}$ HD detected at $6 \mathrm{~h}$, although with $10 \mathrm{mM}$ GSH there was some associated toxicity detected, even in the control, which diminished some of the dose-related benefits seen with the lower concentrations of GSH (Table 2). 
Table 1. Effects of buthionine sulfoximine (BSO) and $N$-acetylcysteine (NAC) on sulfur-mustard (HD) treated endothelial cells ${ }^{\mathbf{a}}$

\begin{tabular}{|c|c|c|c|c|c|c|}
\hline & & Con & & & $500 \mu \mathrm{M}$ & \\
\hline & $\% \mathrm{~V}$ & $\% A$ & $\% \mathrm{~N}$ & $\% \mathrm{~V}$ & $\% A$ & $\% \mathrm{~N}$ \\
\hline Untreated & $90.3 \pm 3.1$ & $3.6 \pm 2.1$ & $6.1 \pm 2.8$ & $50.4 \pm 4.0$ & $33.1 \pm 5.0$ & $16.3 \pm 4.5$ \\
\hline $0.2 \mathrm{mM}$ BSO & $91.0 \pm 3.0$ & $2.7 \pm 0.6$ & $6.3 \pm 3.1$ & $35.7 \pm 8.4$ & $32.7 \pm 10.3$ & $31.7 \pm 17.8$ \\
\hline $50 \mathrm{mM}$ NAC & $93.3 \pm 3.6$ & $2.5 \pm 1.0$ & $4.3 \pm 2.6$ & $69.3 \pm 1.7$ & $21.2 \pm 4.3$ & $9.5 \pm 4.4$ \\
\hline $\mathrm{BSO}+\mathrm{NAC}$ & $92.7 \pm 4.0$ & $2.0 \pm 1.0$ & $5.3 \pm 3.2$ & $51.7 \pm 4.7$ & $37.0 \pm 5.7$ & $11.3 \pm 1.2$ \\
\hline
\end{tabular}

${ }^{a}$ Confluent endothelial cells were pretreated with or without $0.2 \mathrm{mM}$ BSO for at least $6 \mathrm{~h}$ prior to treatment with or without $50 \mathrm{mM}$ NAC for $16 \mathrm{~h}$. The medium was changed, followed by treatment with or without $500 \mu \mathrm{M}$ HD for $6 \mathrm{~h}$. Cell viability was determined as described in Methods and Materials: V, viable; A, apoptotic; N, necrotic. Values reported as mean \pm SD $(n=4)$.

Table 2. Effect of exogenous glutathione (GSH) on sulfur-mustard (HD)-induced injury in endothelial cells ${ }^{\mathrm{a}}$

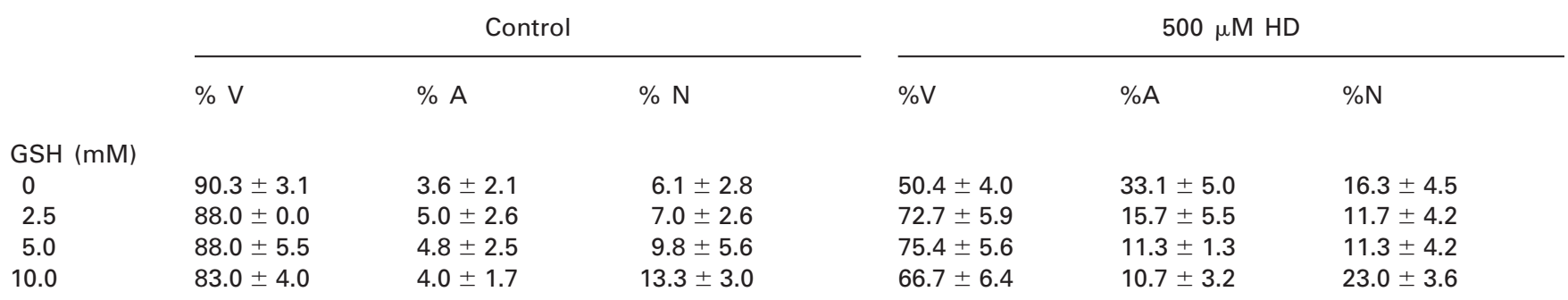

a Confluent endothelial cells were pretreated with $0-10 \mathrm{mM} \mathrm{GSH}$ for $1 \mathrm{~h}$. The cells were then treated with or without $500 \mu \mathrm{M}$ HD for $6 \mathrm{~h}$ without a medium change. Cell viability was determined as described in Methods and Materials: V, viable; A, apoptotic; $\mathrm{N}$, necrotic. Values reported as mean $+\mathrm{SD}(n=4)$.

Effects of glutathione-altering agents on total cellular glutathione levels in sulfur-mustardinjured endothelial cells

When intracellular GSH levels were measured, it was determined that NAC pretreatment alone was associated with an approximate $60 \%$ increase in GSH levels in uninjured endothelial cells (Fig. 1). Treatment with BSO alone or in combination with NAC in uninjured endothelial cells was associated with a substantial reduction of approximately $60 \%$ of total intracellular

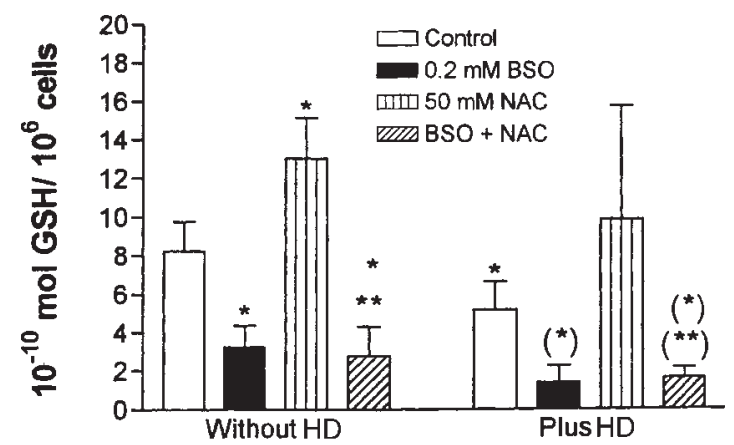

Figure 1. Effects of buthionine sulfoximine (BSO) and $\mathrm{N}$-acetylcysteine (NAC) on glutathione (GSH) levels in endothelial cells. Cells were treated with or without $0.2 \mathrm{mM}$ BSO for $6 \mathrm{~h}$ prior to additional treatment with or without $50 \mathrm{mM}$ NAC for $16 \mathrm{~h}$. The medium was changed and cells were treated with or without $500 \mu \mathrm{M}$ HD for $6 \mathrm{~h}$. Total cellular GSH was determined as described in Methods and Materials $(n=3):{ }^{*} P \leqslant 0.02$ vs $(-\mathrm{HD})$ control; ${ }^{* *} P \leqslant 0.005$ vs $(-\mathrm{HD})$ NAC; $(*) P \leqslant 0.02$ vs $(+\mathrm{HD})$ control; $(* *) P \leqslant 0.005$ vs $(+\mathrm{HD}) \mathrm{NAC}$.
GSH levels. Total GSH levels following exposure to $500 \mu \mathrm{M}$ HD were reduced significantly in endothelial cells (ca. 40\%), but were substantially preserved in endothelial cells pretreated with $50 \mathrm{mM}$ NAC prior to HD exposure (Fig. 1).

\section{Effect of Sulfur mustard on nuclear transcription factor NFkB activity in endothelial cells}

Nuclear transcription factor $\mathrm{NF \kappa B}$ activity was measured using electrophoretic mobility shift assays in experiments where endothelial cells were exposed to 250 or $500 \mu \mathrm{M}$ HD and nuclear extracts were made at 2 or $5 \mathrm{~h}$ after exposure to the vesicant with or without prior treatment with $50 \mathrm{mM}$ NAC. An increase in $\mathrm{NF \kappa \textrm {B }}$ binding to its consensus sequence was detected in extracts taken from cells exposed to $500 \mu \mathrm{M}$ HD as early as $2 \mathrm{~h}$, with an increase seen at $5 \mathrm{~h}$. The NAC treatment in combination with HD exposure was associated with variable effects on the NFкB activity induced by HD alone (Fig. 2). Not until $5 \mathrm{~h}$ after exposure to $500 \mu \mathrm{M}$ HD was there any inhibitory effect $(88 \%$ reduction in $\mathrm{NF \kappa B}$ activity vs HD alone by scanning densitometry) of NAC treatment on NFkB activity (Fig. 2). Interestingly, NAC treatment alone was associated with a $52 \%$ increase in NFKB activity compared with the control (Fig. 2). 


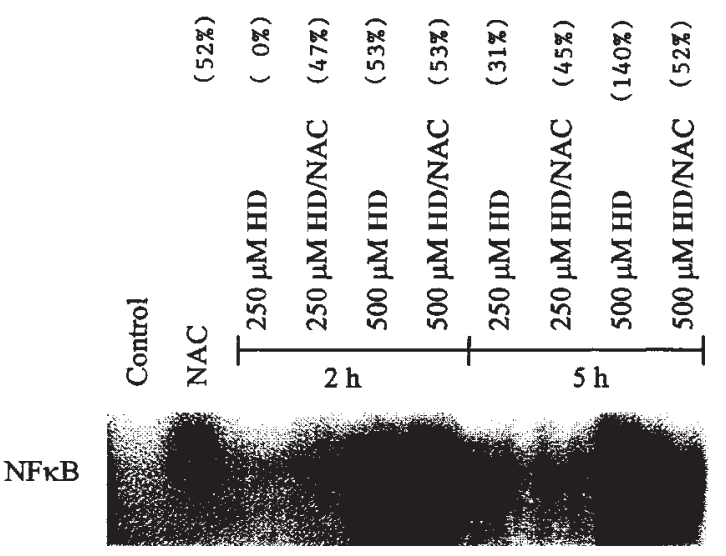

Figure 2. Electrophoretic mobility shift analysis of nuclear extracts of endothelial cells exposed to sulfur mustard (HD). Confluent endothelial cells were pretreated with or without $50 \mathrm{mM} \mathrm{N}$-acetylcysteine (NAC) for at least $16 \mathrm{~h}$. Cells were then treated with 0,250 or $500 \mu \mathrm{M}$ HD for 2 or $5 \mathrm{~h}$ without a medium change. Nuclear extracts were prepared and $5 \mu \mathrm{g}$ of protein was incubated with a ${ }^{32} \mathrm{P}$-labeled consensus NFKB oligonucleotide $(30000 \mathrm{cpm})$ for $20 \mathrm{~min}$ at room temperature. The binding reactions were then resolved by polyacrylamide gel electrophoresis and exposed to X-ray film at $-70^{\circ} \mathrm{C}$. Numbers in parentheses represent the percentage increase of each band compared with the control as determined by scanning densitometry.

\section{DISCUSSION}

In this study we have confirmed and extended the work of others demonstrating that exogenous GSH exerts marked protective effects in cellular injury secondary to HD exposure. The experiments with the GSH-altering agents, NAC and BSO, confirm that at least part of the beneficial effect of NAC on endothelial cell survival following HD injury is directly related to its stimulatory effect on GSH synthesis, because inhibition of the stimulatory effects of NAC on GSH synthesis by concurrent treatment with BSO abrogated any beneficial effects on endothelial cell viability and total GSH levels.

Our preliminary observations with electrophoretic mobility shift assays of nuclear extracts from endo- thelial cells following HD treatment suggest that HD can lead to activation of the nuclear transcription factor

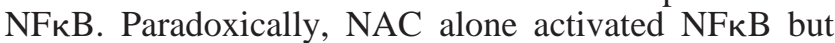
also demonstrated substantial inhibitory effects on $\mathrm{NF} \kappa \mathrm{B}$ activation in cells exposed to $500 \mu \mathrm{M}$ HD later $(5 \mathrm{~h})$ in the time course of injury. Paradoxical effects of NAC in other biological systems in which oxidant generation was enhanced under some conditions by NAC are consistent with these observations. ${ }^{17}$ Using a scopoletin assay, ${ }^{18}$ we have found in a cell-free system that oxidation of scopoletin nearly doubles when $50 \mathrm{mM}$ NAC is present (unpublished observations). Competing effects of NAC, such as oxidative activation of $N F \kappa B$ versus enhanced reducing capacity within the cell as a result of NAC-enhanced GSH synthesis, may account for these puzzling observations. Taken together, these observations suggest that agents that can stimulate GSH synthesis within potential target cells of HD injury may enhance cellular survival by increasing cellular levels of GSH, a potential scavenger of $\mathrm{HD}$, as well as inhibiting activation of the nuclear transcription factor $\mathrm{NFKB}$, which is an important regulator of the expression of a number of endothelial-cellderived cytokines. These cytokines (e.g. tumor necrosis factor, TNF) play critical roles in amplifying inflammatory responses involving injured endothelium and may even play an important role in potentially acting as autocrine signals in the pathways governing programmed cell death. Redox-active compounds, which stimulate intracellular GSH synthesis and also limit activation of the nuclear transcription factor $\mathrm{NF \kappa B}$, may be particularly helpful as chemical countermeasures to the toxic effects of the vesicant HD.

\section{Acknowledgements}

This work was supported by the US Army Medical Research and Material Command under contract MIPR CVEM6785 and in part by the Department of Veterans Affairs. The views, opinions and/or findings contained in this report are those of the authors and should not be construed as an official Department of the Army position, policy or decision unless so designated by other documentation.

\section{REFERENCES}

1. Papirmeister B, Gross $\mathrm{CL}$, Meier $\mathrm{HL}$, Petrali JP, Johnson JB. Fundam. Appl. Toxicol. 1985; 5: S134-S149.

2. Papirmeister B, Feister AJ, Robinson SI, Ford RD. Medical Defense Against Mustard. CRC Press: Boca Raton, FL, 1991.

3. Hinshaw DB, Lodhi IJ, Hurley LL, Atkins KB, Dabrowska MI. Toxicol. Appl. Pharmacol. 1999; 156: 17-29.

4. Dabrowska MI, Becks LL, Lelli JL, Levee MG, Hinshaw DB. Toxicol. Appl. Pharmacol. 1996; 141: 568-583.

5. Tsai J-C, Jain M, Hsieh C-M, Lee W-S, Yoshizuma M, Patterson C, Perrella MA, Cooke C, Wang H, Haber E, Schlegel R, Lee M-E. J. Biol. Chem. 1996; 271: 3667-3670.

6. Black RM, Brewster $\mathrm{K}$, Clarke Rj, Hambrook JL, Harrison JM, Howells DJ. Xenobiotica 1992; 4: 405-418.

7. Davison C, Rozman RS, Smith PK. Biochem. Pharmacol. 1961; 7: 64-74.

8. Langford AM, Hobbs MJ, Upshall DG, Blain PG, Williams FM. Hum. Exp. Toxicol. 1996; 15: 619-624.

9. Ray R, Legere RhH, Majerus BJ, Petrali JP. Toxicol. Appl. Pharmacol. 1995; 131: 44-52.
10. Gross CL, Innace JK, Hovatter RC, Meier HL, Smith WJ. Cell Biol. Toxicol. 1993; 9: 259-267.

11. Smith CN, Lindsay CD, Upshall DG. Hum. Exp. Toxicol. 1997; 16: 247-253.

12. Wilde PE, Upshall DG. Hum. Exp. Toxicol. 1994; 16: 247253.

13. Sen CK, Khanna S, Reznick AZ, Roy S, Packer L. Biochem. Biophys. Res. Commun. 1997; 237: 645-649.

14. Griffith OW. Anal. Biochem. 1980; 106: 207-212.

15. Scheiber E, Matthias P, Muller MM, Schaffner W. Nucleic Acid Res 1989; 17: 6419.

16. Dignam JD, Lebovitz RM, Roeder RG. Nucleic Acid Res. 1983; 11: 1475-1489.

17. Sprong CR, Winkelhuyzen-Janssen ML, Aarsman CJM, VanOirschot JFLM, Van der Bruggen T, Sweder van Asbeck B. Am. J. Respir. Crit. Care Med. 1998; 157: 1283-1293.

18. DeLaHarpe J, Nathan CF. J. Immunol. Methods 1985; 78: 323-336. 